\title{
Keeping Up to Date on Climate Change
}

\section{Barrie Pittock \\ Honorary Fellow, CSIRO Marine and Atmospheric Research, Private Bag 1, Aspendale 3195, Australia}

Climate change has in the last 12 months reached the headlines after a gestation period of decades. It is high on the policy list for governments and now even the most sceptical politicians have accepted its reality, if not the urgency of measures to reduce its magnitude and adapt to what is unavoidable. This article will attempt to summarise recent findings and points to the need for urgent risk minimisation. In early 2007, the Intergovernmental Panel on Climate Change (IPCC), the world's leading scientific body on climate change, released the Summary for Policymakers of each of three Working Group reports. These reports form part of the IPCC's Fourth Assessment.

In brief, the reports state with high confidence that climate change is happening and the warming of the world over the last several decades, is largely due to human emissions of greenhouse gases (GHGs). Climate change is already having noticeable effects, which are likely to increase to potentially dangerous dimensions by or earlier than 2100 , unless greenhouse gas emissions are greatly reduced. Moreover, the IPCC says that impacts are very likely to cause costs that will increase as global warming increases, but that there is substantial potential for reductions in emissions at little cost to the economy, with many examples given. It reports that global costs of emission reductions to achieve stabilisation of GHG concentrations at levels between 445 and 710 ppm C02 equivalent would range between a 5\% loss and a 1\% gain in global Gross Domestic Product (GDP) in 2050. This is less than a tenth of one percent of the growth in GDP by 2050 .

In agreement with the Stern Report issued in the UK during 2006, the IPCC Working Group HI report confirms that potential costs of the impacts of unabated climate change and sea level rise would far exceed the costs of reducing greenhouse gas emissions to avoid the impacts.

\section{BACKGROUND}

Scientists chosen to write IPCC reports are appointed on the basis of their relevant expertise. Exhaustive processes of peer and government review are followed, with responses to all comments documented and archived for transparency. More than 2000 scientists from many countries are directly involved. The final documents are the responsibility of the scientist authors, but the Summaries for Policymakers are subject to agreement line-by-line by government representatives, including countries as disparate in their views and interests as the UK, Germany, Russia, the United States, China, India and Australia. As mis final "plenary review" is based on consensus and the agreement of the scientist authors, no single extremist position is possible.
This does not mean that political influence is entirely absent: compromises are reached on some issues, but these have to be agreed to by the scientist authors.

Changes are invariably matters of emphasis or expression rather than of facts. IPCC is charged with preparing reports that are relevant to policy but do not tell governments or people what to do. Three factors have tended to create difficulties in providing the best advice:

- A tendency for many scientists involved in these Assessments to concentrate on "best estimates" in which they have most confidence, rather than on less certain possibilities that may be more serious in their impacts. The latter are important in risk management, since they identify and hopefully quantify more extreme possible outcomes that should be avoided by policy actions.

- A tendency for many scientists to only state numerical conclusions that come from processes explicitly included in numerical models of climate and sealevel rise. Other processes may be known to be occurring, with possibly large impacts, but if these are not already in the numerical models the magnitude and likelihood of their impacts cannot be confidently stated. How these unqualified possibilities are dealt with in reports can be critical.

- The cut-off date for publications considered in any report is set so that any statements based on recent work have been reviewed by relevant experts apart from those drafting the Assessments. Thus some details of the reports become out of date before they appear in print.

The IPCC Assessments are very different to the dayto-day work of a "normal" scientist. In her/his dayto-day work, a scientist is looking for cutting edge results and theories. In IPCC Assessments the same scientist is looking for what is generally agreed across the field and is well supported by multiple lines of evidence and by multiple publications in the scientific, peer-reviewed literature. IPCC aims to identify the "gold standard" science, rather than the "leading edge" science. Conclusions from the IPCC reports have to be considered in the light of these factors.

\section{KEY FINDINGS OF THE IPCC REPORTS}

\section{Working Group I : The Physical Science Basis (IPCC, 2007a)}

- Concentrations of GHGs now far exceed preindustrial values and the increases are due primarily 
to fossil fuel usage and land-use change and agriculture.

- There is now very high confidence that the global average effect of human activities since 1750 has been one of warming of about $0.8^{\circ} \mathrm{C}$. Global warming is unequivocal, and is now evident in air and ocean temperatures, widespread melting of snow and ice, and rising global sea levels due to thermal expansion and ice melt.

- Numerous long-term changes in regional climate have been observed including higher temperatures and reduced sea ice in the Arctic, changes in precipitation, ocean salinity, wind patterns and weather extremes including drought, heavy rains, heat waves and intensity of tropical cyclones.

- For a doubling of atmospheric carbon dioxide, stabilised warming is likely to be in the range 2 to $4.5^{\circ} \mathrm{C}$. It is very unlikely to be less than $1.5^{\circ} \mathrm{C}$ but warmings substantially higher than $4.5^{\circ} \mathrm{C}$ cannot be excluded.

- For the next 20 years warming of about another $0.4^{\circ} \mathrm{C}$ is inevitable for the IPCC range of emissions, due to past emissions and lags in the climate system. Continued greenhouse gas emissions at or above current rates would cause further warming during the 21 st century. For the full range of the IPCC emissions scenarios, the lowest plausible warming by 2100 is about $1.1^{\circ} \mathrm{C}$ relative to the $1990 \mathrm{~s}$ and the highest is about $6.4^{\circ} \mathrm{C}$.

- Projected sea level rises by 2100 are estimated to be in the range 18 to $59 \mathrm{~cm}$, mainly due to thermal expansion of the oceans and a contribution from melting mountain glaciers. These estimates do not include uncertainties in climatecarbon cycle feedbacks, nor the full effects of changes in ice dynamics, because these are not yet included in the models. If ice flow rates continue to increase in Greenland and Antarctica significantly higher sea level rise might occur, which IPCC estimates could be up to an additional $20 \mathrm{~cm}$ by 2100. 125,000 years ago, when polar regions were warmer than now, sea level was 4 to 6 metres higher.

- Increased atmospheric carbon dioxide concentrations have led to increased acidity in the oceans. Further acidification is likely to occur over the 21 st century, sufficient to inhibit coral growth and shell-formation in many oceanic species.

- There is now higher confidence in projected patterns of warming, changes in wind patterns, precipitation, some aspects of extreme events and ice. Even if greenhouse gas concentrations are stabilised, warming and sea level rise would continue for centuries, due to the long timescales of climate processes and feedbacks,

- In Australia, tropical cyclones are likely to be more intense, heat waves and heavy precipitation events more frequent, and extra-tropical storm tracks and wind and precipitation patterns will move further poleward.

\section{Working Group II: Impacts, Adaptation and Vulnerability (IPCC, 2007b)}

- Observations from all continents and most oceans show natural systems are being affected by regional climate changes, especially warming. This includes snow, ice and permafrost, land and ocean species and ecosystems and ocean acidity. 67 of 75 studies involving 29,000 data series of physical and biological systems and species, show changes consistent with a response to warming. Effects of regional climate changes on human and managed systems are emerging, but are complicated by adaptation and nonclimatic stresses (e.g. land-use change, population growth).

- Future impacts can now be projected for many sectors, e.g. increased runoff at high latitudes, decreased runoff and drought in some mid-latitudes, loss of seasonal water storage in snow and glaciers, loss of species and ecosystems, reduced crop productivity at low latitudes and at mid-latitudes with larger warmings, increased coastal erosion and flooding, displacement of many coastal populations, increased vulnerability of many settlements and industries, and increased threats to health especially in poor countries.

- Specific information is available for many regions. Impacts on Australia will include: water problems in southern and eastern Australia, and significant losses of biodiversity in the Great Barrier Reef, the Queensland Wet Tropics, Kakadu, south-western Australia, alpine areas and the sub-Antarctic islands. Coastal development and population growth in many coastal areas will amplify losses from sealevel rise and increased severity of storms and coastal flooding. Productivity from agriculture and forestry is expected to decline by 2030 over much of southern and eastern Australia due to increased drought and fire. While substantial adaptive capacity is available, there will be increasing costs associated with adaptation and from failure to fully adapt.

- Regions other than Australia will also experience significant problems, with increasing malnutrition in Africa, displacement of many coastal people from large deltas and small islands in many countries, low adaptive capacity in many poor countries and increasing financial expense and losses even in rich countries, especially from impacts of extreme events.

- Key impacts are expected to increase with increasing global warming, becoming very widespread and serious at warmings of only 2 or $3^{\circ} \mathrm{C}$ above temperatures of the 1990s. This is especially true of impacts from extreme events. Climate change impacts are very likely to impose net annual costs that will increase over time as global warming increases.

- Some large-scale climate events have the potential to cause very large global impacts, especially beyond 2100 . Sea level rise of up to $7 \mathrm{~m}$ from melting of the Greenland Ice Sheet, and $5 \mathrm{~m}$ from 
melting of the West Antarctic Ice Sheet is possible over timescales of centuries to millennia, possibly triggered by warming in the 21 st century. Slowing of the rate of sinking of cold saline water in the North Atlantic is very likely during the 21 st century, with widespread impacts on marine ecosystems, fisheries, ocean uptake of carbon dioxide, oceanic oxygen concentrations and terrestrial vegetation.

- Adaptation is necessary to address impacts resulting from the warming that is already unavoidable due to past (and continuing) emissions. A wide array of adaptation options is available, but more is required. There are barriers, limits and costs to adaptation, but these are not fully understood.

- Other stresses such as pollution, poverty and inappropriate development (e.g. rapid population growth) increase vulnerability to climate change. Sustainable development can reduce vulnerability to climate change, while climate change can impede sustainable development.

- Many impacts can be avoided, reduced or delayed by reducing GHG emissions.

\section{Working Group III : Mitigation of Climate Change (Reducing Emissions and Mitigating Impacts) (IPCC, 2007c)}

- Global GHG emissions per annum (weighted by their respective global warming potentials) have increased by $70 \%$ between 1970 and 2004 and will continue to grow under current policies.

- There is substantial economic potential for limiting or reducing GHG emissions over the coming decades, even below current levels. Key technologies for reducing emission of GHGs are available in all relevant sectors including energy supply, transport, buildings, industry, agriculture, forestry and waste, and also through nontechnological means such as life style changes and management practices.

- These technologies will often have other benefits. For example, improvements in energy facilities can create opportunities to reduce $\mathrm{GHG}$ emissions, and at the same time reduce air pollution, improve the balance of trade, and provide better services in rural areas and increased employment.

- Geo-engineering options such as ocean fertilisation to remove atmospheric $\mathrm{C} 02$, or blocking sunlight in the upper atmosphere remain largely speculative and unproven, with unknown side effects and costs.

- In order to stabilise GHG concentrations in the atmosphere and thus eventually the climate, emissions must peak and then decline. The lower the needed stabilisation level, the sooner the peak and decline must occur. Emissions reductions over the next two or three decades will have a large impact on opportunities to reach lower levels.

- Stabilisation of atmospheric GHG concentrations in the low range of 445-490 ppm C02 equivalent would still lead to eventual global wanning in the range of about $1^{\circ}$ to $3^{\circ} \mathrm{C}$ (which entails a risk of causing "widespread and serious" climate change). (This is actually a WGI result, but does not appear in the WGI SPM Summary despite its critical importance for policy. It is in the WGIII)

Figure SPM 8. What is "dangerous" is a subjective judgement. 2 To reach the lower stabilisation levels some scenarios depend upon removal of $\mathrm{C} 02$ from the atmosphere (negative emissions).

- The range of stabilisation levels assessed by IPCC can be achieved with a portfolio of technologies, assuming appropriate incentives are in place for their development and deployment. Global costs of emission reductions to achieve stabilisation of $\mathrm{GHG}$ concentrations at levels between 445 and 710 ppm $\mathrm{C} 02$ equivalent would range between a $5 \%$ loss and a $1 \%$ gain in GDP in 2050. This is less than a tenth of one percent of the growth in GDP by 2050 .

- Choosing an appropriate level of global emissions reductions over time is a risk management process. It involves balancing the costs of more rapid emission reductions now against the longer-term risks from climate change.

- Many national policies and instruments are available to governments to create the incentives for reducing emissions. Each of these has advantages and disadvantages. All approaches (such as regulations and standards, taxes and charges, tradeable permits and other incentives) can be designed well or poorly, and be stringent or lax.

- Policies that provide a price on carbon emissions could create incentives for producers and consumers to invest in low-GHG products, technologies and processes. However, many barriers to implementation of emission reduction policies exist.

- Government support through financial contributions, tax credits, standard setting and market creation is important for effective technology development, innovation and deployment, and for transfer to developing countries.

- The United Nations Framework Convention on Climate Change and its Kyoto Protocol stimulated an array of national policies, created an international carbon market and established new mechanisms that may provide the foundation of future emissions reduction efforts. There are many options for reducing $\mathrm{GHG}$ emissions globally through international cooperation.

- Changing the pattern of development to make it more sustainable can make a major contribution to emissions reductions but extra resources may be needed to overcome barriers. Observations suggest changes are happening faster than the IPCC midrange

As noted above, there are several key reasons why the IPCC reports tend to be conservative: the tendency for scientists to cite the middle of the range of uncertainty, when risk management requires that 
we consider the risk of changes near the top of the range; a hesitance to cite results that are not quantified and thus already in numerical models; and the early cut-off date for publications considered in IPCC reports in order that they can be fully reviewed by peer reviewers. In the case of the 2007 IPCC reports, this means that only papers published up to about mid-2006 were considered. However, several important papers have appeared since then.

Rahmstorf (2007) made an estimate of the sea-level rise by 2100 based on correlations between observed global warming relative to pre-industrial for each decade since 1881 and observed sealevel rise for the same decades. Using this relationship and the IPCC range of emission scenarios for global warming he estimates the range of sea-level rise as 50 to $140 \mathrm{~cm}$ by 2100 , which is much larger than the IPCC estimates. Rahmstorf assumed a linear relationship between warming and sea-level rise. However, if we assume the relationship accelerates due to various amplifying effects, notably acceleration of outlet glaciers from Greenland and Antarctica, then sea-level rise by 2100 could be several meters (Hansen, 2005, 2007; Hansen et al., 2007). Indeed Hansen (2007) argues that scientists have been too inhibited m communicating the threat of a potentially large rise in sea level. Bamber et al. (2007), state that there is growing evidence that mass loss [from Greenland and the West Antarctic Ice Sheet] has increased in the last decade and it seems likely that this trend will be maintained if the amplified warming in the polar regions continues". They note that present ice-flow models cannot explain the observations, and go on to say that "we are able to confidently state that modernday ice sheets can respond rapidly to external forcing, but if asked "Will ice sheets in the near future respond rapidly...?" we must give a qualified 'maybe'."

More importantly perhaps, Rahsmtorf et al. (2007) reported that carbon dioxide concentrations, global average temperatures and sea-level rise are all tracking since 1990 near the top of the range of estimates from the IPCC range of emission scenarios. This is shown in Figure 1.

There are a number of causes. Firstly, C02 emissions are in fact increasing more rapidly than was expected in most of the IPCC scenarios, due to rapid economic growth rates in many countries, especially major developing countries such as China and India.

Indeed, Raupach et al. (2007) report that C02 emissions from fossil-fuel burning and industrial processes have been accelerating globally, with their growth rate increasing from $1 \%$ per annum for 1990 1999 to $>3 \%$ per annum for $2000-2004$. This is faster than the most fossil-fuel intensive of the IPCC scenarios, and was driven by a cessation or reversal of the earlier decline in the energy intensity of gross domestic product (energy per unit GDP) and the carbon intensity of energy (emissions per unit energy). This is compounded by the continuing increases in population and per-capita GDP. The growth rate in emissions is greatest in developing economies such as China, although emissions are still increasing in most developed countries, which have emitted the bulk of emissions since the industrial revolution.

These developments pose serious issues regarding global equity in any real attempt to reduce global emissions. Another reason for the more rapid warming is that the cooling effect of atmospheric particulates, sometimes referred to as "global dimming", was larger than assumed. It is now decreasing as sources of particulate pollution are brought under control especially in North America and Europe (see Pittock, 2006, 2007).

The rapid rate of climate change is exacerbated by a number of positive feedback or amplifying effects that have been observed to be happening in recent decades (full references in Pittock, 2006 and 2007). Several of these are not yet fully accounted for on the climate models. These effects include:

- Arctic permafrost (frozen ground) and snow cover are decreasing, leading to more absorption of incoming sunlight (e.g. Overland, 2006).

- The living biosphere, particularly forests and soils, are turning increasingly from being absorbers of atmospheric $\mathrm{C} 02$ to being emitters of $\mathrm{C} 02$ due to warming, drought stress of plants and increasing forest and peat fires (e.g. Canadell et al. 2007).

- Artic sea ice is retreating rapidly, leading to more absorption of sunlight and greater regional warming. A very recent paper by Stroeve et al. (2007) states that "none or very few individual model simulations show trends comparable to observations".

- Changes in air and sea circulations in middle and high latitudes are accelerating changes in higher latitudes. Mid-latitude westerly winds in both hemispheres have moved polewards and surface ocean gyres have accelerated affecting the East Australian Current, with more heat transport polewards, possibly adding to destabilisation of the West Antarctic Ice Sheet (e.g. Cai et al., 2005; Fyfe and Saenko, 2006).

- Rapid changes in Greenland and Antarctica, including increased surface melting in summer and undercutting and disintegration of floating ice shelves and tidewater (i.e. floating) glaciers that retard ice outflow. These processes are not included so far in glaciological models (Bamber et al. 2007).

\section{SUMMARY AND CONCLUSIONS}

The Fourth Assessment Report of the IPCC, summaries of which have been released, confirm that global warming is happening and is primarily due to human release of stored carbon from fossil fuels, forests and soils. The science indicates that widespread effects are to be expected, and there is growing evidence from observations that this is happening.

Latest IPCC projections indicate a likelihood of greater global warmings by 2100 than previously 
projected. However, IPCC projections of sea level rise are conservative because they have not quantified the effects of accelerated ice dynamics in Greenland and Antarctica. More recent estimates, based on observations, suggest that sea level rise will be in the range of 50 to $140 \mathrm{~cm}$ by 2100 , but even this may be an under-estimate if outlet glaciers continue to accelerate.

There are a number of processes not yet adequately included in climate and glaciological models, although they have been observed. These inadequately modeled processes are expected to increase the risk of damaging climate change and sea level rise. IPCC $(2007 \mathrm{c})$ calculations broadly confirm the Stern Review (2006) estimates that the damages from potential climate change are likely to be much greater than the cost of reducing greenhouse gas emissions. They also suggest that to avoid a $2-3^{\circ} \mathrm{C}$ global warming above preindustrial values, greenhouse gas concentrations may need to be kept below 450 ppm C02 equivalent (see Figure SPM-8 in the IPCC report). According to IPCC, such a target may require reducing emissions to zero or below, with any delay making the task even more difficult.

These results have been approved, in summary form, by member country governments of the IPCC (including Australia). Thus they can no longer be dismissed as the work of rabid environmentalists, doom-mongers or alarmists. The problem now is not with the science (even though that needs improvement) but with policy-makers. Policy must be about risk management, that is, about how to avoid the unacceptable, not about what is most likely to happen. The real question is no longer whether climate change is happening, but how to adapt to what is now unavoidable, and how to rapidly reduce greenhouse gas emissions so as to avoid what we may not be able to adapt to. A key policy question that follows is how to encourage and enable developing countries to limit their emissions while still enabling them to have rising living standards. These are not easy questions, but hopefully they are not beyond human ingenuity to answer.

\section{ACKNOWLEDGEMENT}

This paper is based on a paper prepared for the Australian Collaboration http://www. australiancollaboration.com.au/factsheets/ index.html. It is reproduced with the Australian Collaboration's permission.

\section{REFERENCES}

Bamber, J.L., R.B. Alley and I. Joughin, 2007: Rapid response of modern day ice sheets to external forcing, Earth and Planetary Science Letters, 257, 1-13.

Cai, W., G. Shi, T. Cowan, D. Bi, and J. Ribbe, 2005: The response of the Southern Annular Mode, the East Australian Current, and the southern midlatitude ocean circulation to global warming, Geophys. Res. Lett., 32, L23706, doi: 10.1029/2005GL024701.
Canadell, J.G, D.E. Pataki, R. Gifford, R.A. Houghton, Y. Luo, M.R. Raupach, P. Smith and W. Steffen, 2007:, Saturation of the terrestrial carbon sink, Chapter 6 in: Terrestrial Ecosystems in a Changing World (ed., Canadell, J.G., D. Pataki and L. Pitelka, Springer-Verlag, Berlin Heidelberg.

Fyfe, J. C., and O. A. Saenko, 2006: Simulated changes in the extratropical Southern Hemisphere winds and currents, Geophysical Research Letters, 33, L06701, doi:10.1029/2005GL025332.

Hansen, J.E., 2005: A slippery slope: how much global warming constitutes "dangerous anthropogenic interference"? Climatic Change, 68, 269-279.

Hansen, J.E., 2007: Scientific reticence and sea level rise, Environmental Research Letters, 2024002 doi: $10.1088 / 1748-9326 / 2 / 2 / 024002$.

Hansen J., M. Sato, and 45 others, 2007: Dangerous human-made interference with climate: AGISS modelE study, Atmospheric Chemistry and Physics, 7, 22872312 .

IPCC, 2007a: Intergovernmental Panel on Climate Change, 4th Assessment Report, Working Group I, The Physical Science Basis, available at http://ipccwgl.ucar.edu/wgl/wgl-report.html

IPCC, 2007b: Intergovernmental Panel on Climate Change, 4th Assessment Report, Working Group II, Impacts, Adaptation and Vulnerability, available at http:/ /www.ipcc. ch/SPM13apr07.pdf. The full report is available at www.ipcc.ch.

IPCC, 2007c: Intergovernmental Panel on Climate Change, 4th Assessment Report, Working Group III, Mitigation of Climate Change, available at http:// www.mnp.nl/ipcc/pages media/AR4-chapters.html

Overland, J.E., 2006: Arctic change: multiple observations and recent understanding. Weather, 61, 7883.

Pittock, A.B., 2006: Are scientists underestimating climate change? EOS (Transactions of the Amer. Geophysical Union), 87 (34), 22 August 2006.

Pittock, A.B., 2007: Ten reasons why climate change may be more severe than projected. In: Sudden and Disruptive Climate Change: Its Likelihood, Character and Avoidance, (M.C. McCracken, J.C. Topping and F. Moore, eds.), Earthscan Pub., London, in press.

Rahmstorf, S., 2007: A semi-empirical approach to projecting future sea-level rise, Science, 315, 368-370. Rahmstorf, S., A. Cazenave, J.A. Church, J.E. Hansen, R.F. Keeling, D.E. Parker and R.C.J. Somerville, 2007: Recent climate change: Observations compared to projections, Science, 316, 709.

Raupach, MR., G. Marland, P. Ciais, C. Le Quere, J.G. Canadell, G. Klepper and C.B. Field,, 2007: Global and regional drivers of accelerating $\mathrm{C} 02$ emissions, Proceeding National Academy of Sciences (USA), 104, 10288-10293.

Stern Review: The Economics of Climate Change, 2006: 
HM Treasury, London, UK. Available at: http:// www.hm-treasury.gov.uk/independent reviews/ stern_review_economics_climate_change/ stern_review_report.cfm.

Stroeve, J., M.M. Holland, W. Meier, T. Scambos and M. Serreze, 2007: Arctic sea ice decline: faster than forecast, Geophysical Research Letters, 34, L09501, doi: 10.1029/2007GL029703.

Figure 1: Changes in key global climate0related variables since 1973, relative to 1990 values, compared with the scenarios developed by IPCC in its 2001 report (dashed lines with gray shading for ranges of uncertainty), which begin in 1990. From Rahmstorf et $a l$. (2007), with permission from Science magazine.

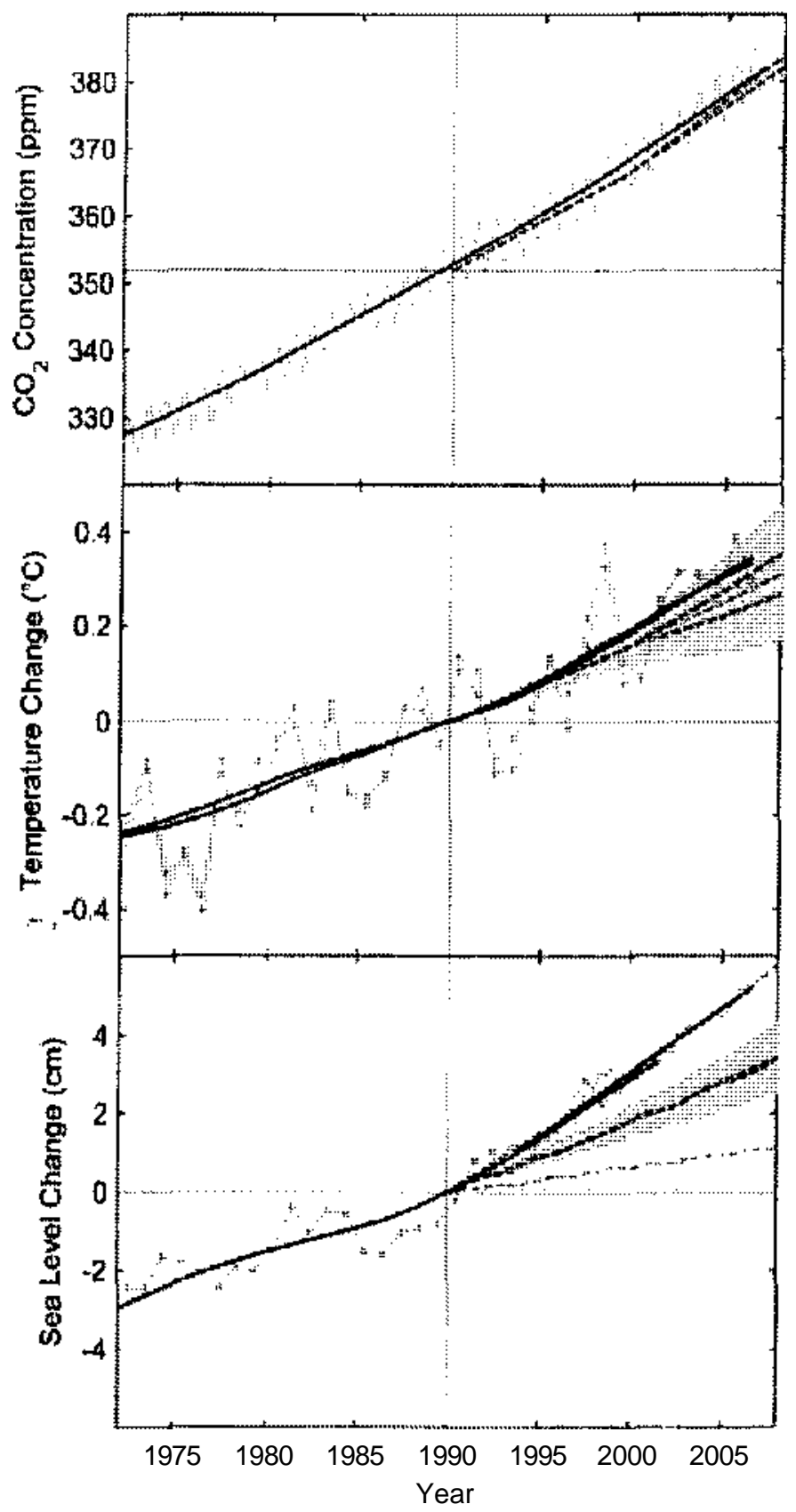

